\title{
COMPARAÇÃO DE ASPECOS FENOLÓGICOS E DE FRUGIVORIA ENTRE Euterpe edulis e Archotophoenix cunnighamiana NO PESM CARAGUATATUBA
}

\author{
Amanda Oliveira da Fonseca ${ }^{1}$ \\ Karolina Marie Alix Benedictte Van Sebroeck Dória²
}

Resumo: A palmeira juçara - Euterpe edulis é considerada de grande importância ecológica para a Mata Atlântica e atualmente encontra-se vulnerável a extinção. A palmeira seafórtia - Archontophoenix cunninghamiana foi introduzida na região pelo atrativo ornamental, atualmente considerada uma espécie exótica invasora. O objetivo deste trabalho foi observar a fenologia, a formação de frutos e descrever o comportamento da assembleia de aves visitantes. Foram demarcados 10 indivíduos adultos de cada espécie de palmeira e estes foram monitorados quinzenalmente entre agosto/2015 a agosto/2016, com observação focal, auxílio de binóculos $8 \times 40$ e registros fotográficos. A A. cunninghamiana ofertou frutos maduros no período de setembro/2015 a maio/2016, enquanto a E. edulis ofertou frutos maduros de fevereiro/2016 a maio/2016. Foram avistadas 141 aves, distribuídas em 8 familias e 19 espécies.

Palavras-chave: Juçara; Seafórtia; Dispersão; Invasão Biológica.

1 Ciências Biológicas/Centro Universitário Módulo/Campus Martim de Sá, Caraguatatuba, Brasil. E-mail: amandafonseca@ymail.com.

2 Ciências Biológicas/Centro Universitário Módulo/Campus Martim de Sá, Caraguatatuba, Brasil. E-mail: karolina.doria@modulo.edu.br. 